\title{
Brief Review of the Philosophical Thought of Wang Fu in "A Treatise on the Latent Man"
}

\author{
Jiang Zefeng \\ (Department of Ideological and Political Theory Teaching, Tonghua Normal University, Ji lin \\ Tonghua 134002)
}

Keywords: Wang Fu; A Treatise on the Latent Man; philosophical thought

\begin{abstract}
Although there were little papers that Wang $\mathrm{Fu}$ specially discussed philosophical problems in "A Treatise on the Latent Man", they contained rich philosophy thoughts. His viewpoints about "Theory of Vitality Primitive", "Epistemology", "Contradiction View", "Conception of Society and History" and "Atheism" had embodied initially the ideological characteristics of naive materialism and naive dialectics.

Although there were little papers that Wang Fu specially discussed philosophical problems in "A Treatise on the Latent Man”, they contained rich philosophy thoughts. He was a political thinker with critical spirit. At the same time, he also was a real philosophical thinker.
\end{abstract}

\section{“Theory of Vitality Primitive”}

The philosophical thought of Wang Fu involved many aspects of the discussion of Han dynasty philosophy. Among them, "Theory of Vitality Primitive" not only enriched the universe theory of Han dynasty, but also reached the highest peak of "Theory of Vitality Primitive" of the Han dynasty philosophy in theory. In the period of two Han dynasties, the concept of all kinds of gas appeared in pre-Qin period was assimilated by "Theory of Vitality" of two Han dynasties. Vitality was the origin of the universe. It also was the most basic and primitive matter that constituted the universe. This was called "Theory of Vitality Primitive" by later generations. There were obvious difference between "Theory of Vitality Primitive" and "Ontology of Vitality". ${ }^{[1]}$ The former, namely vitality monism, considered that vitality was the origin of the universe, and the whole creation was derived from it. Its evolution is as follows:

$$
\begin{gathered}
\nearrow \text { gas } \rightarrow \text { Yang-qi } \rightarrow \text { heaven } \searrow \\
\text { vitality } \begin{array}{c}
\text { creation(human) } \\
\searrow \text { foul air } \rightarrow \text { Yin-qi } \rightarrow \text { earth } \nearrow
\end{array}
\end{gathered}
$$

"Theory of Vitality Primitive", namely monism of Vitality, considered that Vitality was the noumenon of the universe, and the whole creation was Vitality in nature. These matters that people could see and touch were held together by Vitality. And the space also is full of gas. Its diagram was as follows:

$$
\text { vitality }{ }^{\rightarrow} \text { creation }
$$

Zhang Heng, Yang Xiong, Wang Chong, and others all had discourses on vitality. Yang Xiong regarded "Xuan" as the fundamental. He generalized the evolutionary process of universe to the xuan - vitality - everything. Zhang Heng talked about vitality with Tao. He put forward a universe development pattern of Tao - vitality - everything. Wang Chong thought that vitality run through the nature and human society. Due to the heaven and earth on the vitality was basis, so the universe development pattern of Wang Chong was "the Origin Theory of Heaven and Earth" of heaven and earth- vitality - everything. ${ }^{[2]}$ Thus, the two Han dynasties thinkers mentioned above thought that vitality was a naturally existing substance, and run through the whole human society and nature. The change of vitality created everything in the world. But the highest level in the universe model was not vitality. Wang Fu completely overturned the existence of the super strength before gas at the earliest, and systematically elucidated the process of vitality producing all things. Hence, Wang 
$\mathrm{Fu}$ became the symbolic representative person of "Theory of Vitality Primitive" in Chinese philosophy. "A Treatise on the Latent Man, Ben Xun” said: "The world of ancient times, too, from Yao, not visible signs, fine merger, mix into a, mo mo royal. If time, has since, QingZhuo respectively, into a Yin and Yang. Functioning of Yin and Yang managed a two meter, heaven and earth one depression, materialized chun, and strangers with the unification principle." It was said that, in ancient times, only the vitality existed in the universe. It too element of chaos was the starting point of the universe. This kind of vitality that was endless, shapeless, not controlled by any force, went through its movement and finally formed Yin and Yang two gas. The paradoxical movement of Yin and Yang two gas produced all things. The gas of neutralization produced human beings, and human beings dominated and controlled the nature. Thus it can be seen that this statement was not created by predecessors. It had opened up from "Theory of Vitality Primitive". Wang Bugui said: "Wang Fu's matter view was the production of his time, science, and class struggle, and was generalization and crystallization of that era experience". ${ }^{[3]}$ Wang Fu's "Theory of Vitality Primitive" was an indispensable important part in the development of gas theory. It had great effect on later generations. Ji Kang and Liu Zongyuan were affected by the gas theory. It made a significant contribution to the development of Chinese philosophy.

\section{“Epistemology”}

Wang Fu's "Epistemology” influenced by his cosmology, reflected the basic characteristic of materialism epistemology. He denied the transcendentalism of idealist, and thought that human knowledge was acquired by learning, not inborn with knowledge. Even the saints also needed to study to acquire achievements. Under the guidance of thought that "We hope you use the right theories to control your own thoughts and actions, not only use water to mirror his own image" ("E Li”), Wang $\mathrm{Fu}$ thought the acquired knowledge mainly was studying the saint's classic, consequently got the indirect knowledge. This rational indirect knowledge embodied Tao was far deeper than the perceptual direct knowledge. To test of the authenticity of knowledge, Wang $\mathrm{Fu}$ thought the best way was "investigate and check". He advocated "When talking about people, we must conduct evaluation according to him ambition. While slandering or praising them, we must firstly examine and investigate evidence; Don't follow the secular to echo, do not follow other people's arguments to respond" (" communication "), "So people with title must be competent, and people engaged in the management must make the grade." (" Kao Ji ").

\section{“Contradiction View”}

Wang Fu thought that the objective world was full of contradictory phenomena. Such as "Kao Ji": "People recommended by All officials, some delayed by ignorance to apply for alum, some with cruel apply for the very filial piety, some with greed apply for honest and upright officials... some with timid apply for warriors. The name and nature was not consistent; solicitation and election statements did not agree." At the same time, the contradiction between the two sides had irreconcilability. Such as "Shen Wei": "The evil and good, just like water and fire, have different root cause, thus they can't be strong at the same time." "Qian Tan": "it is incompatibility that the Righteous Men and the evil ones.” In addition, the two incompatible parties also had unbalance. But under certain conditions they can be transformed. Such as "Ben Zheng": "The base person and aboveboard gentleman cannot coexist. So, look at the people who had gathered their prince, then whether the country prosperity or decline, you can see out naturally.”

\section{“Conception of Society and History"}

Because of Wang Fu's fundamental philosophical thought had the characteristics of naive materialism and simple dialectic method. This fundamentally determined that his "Conception of Society and History" was developing and change. Wang Fu thought that human society was constantly development and change. And its development depended more on human itself. The 
monarch, country, and laws were not existed since the beginning. They were produced due to changing with times and adapting to the needs of maintaining a certain social order. But with the development of era, the rise and fall of social change, the feudal ethical, legal, customs, state of mind reflected in society were different. So when administering the country, you must grasp the current affairs and be good at changing with things. However there were unreasonable factors in his "Conception of Society and History", such as the using of the cycle historical pattern of "Five De Always".

\section{“The Anti-Superstition Atheism Thoughts”}

The process of analyzing and elaborating the four related superstition problem in "Bu Lie", "Wu Lie", "Xiang Lie" and "Meng Lie" of Wang Fu reflected his certain tendency of atheism thoughts. He also was a comprehensive critique of theological superstition atheistic thinkers after Wang Chong in Han period. According to the established habits after the liberation of our country, the narrow superstition, specifically refer to the thoughts and behaviors that people believe astrology, witchcraft, geomancy, risked and pirates. Superstition itself is not the opposite of scientific knowledge system, but a thinking mode of understanding things with a wrong way. In the society of low level of social productive forces, people meeting and understanding the outside world are extremely limited. When facing the great nature and unknown space, people often obtain their cognitive conclusions. Such as, when saw the basic natural phenomena of thunder, electricity, wind and rain the ancients were unable to make scientific explanations. Finally the cause of all these phenomena was attributed to the supernatural power of god. Thus the early worship of nature forces was formed. With the development of the society, the concern degree of people for their fates was continually deepening. However, they suffered from no clear cognition to the regulation of social development, and they also cannot grasp their own future and destiny, so that it forced people produced a strange good feeling to some supernatural power. On the disposing to some specific problems, they were very passionate about this mysterious force. Then, all kinds of superstitious ideas were prevail, even seriously affected the normal daily life of people. Wang Fu described the social status of the east Han dynasty in article "Fu Chi". "Now most of the women don't do housework, but yet learn and engage in business of witch. They play the drums, dance and serve gods, in order to cheat and deceive people.... Some people abandoned the doctors and medicine, but to go to the gods. So until death, they also don't know they were cheated and delayed by the witch. But instead, they regret it's too late to seek help from the witch. This is the thing that confused people in the most serious fraud game." When talking about the causes of this phenomenon, Wang Fu thought these superstitions problem did not directly make a thorough negation. As Zhou Guixi said that directly repudiate superstition may be no market in society, also can't get people's approval. Wang Fu adopted the progressive argument method in dealing with the problem. He first admitted the effect of these thoughts. Such as discuss the issue of divination. "Bu Lie": "When heaven and earth opened up, god and people had existed. People and god cause was different but essence was same. Behavior can invite humiliation or bring disaster, while fate may encounter unexpected misfortune or flow with one's behavior. For the prediction of lucky or dangerous things, even the indication of heaven, was hard to believe. Although Sages had penetration, they didn't make an arbitrary decision. So they set up divination methods to ask gods.” This showed that Wang $\mathrm{Fu}$ admitted that the divination ideas which were come down by ancestors were the bridge of communication between man and god. Next the elaborated has become: although saint created these means of divination, not everything appealed to divination. The following three articles also held this view. Such as in "Wu Lie", Wang Fu pointed out the witchcraft had certain supplementary role. But it did not fundamentally change the fate of the human. Walker, own quality also; life, a system is of the sky. Is oneself person, solid can be also; that day, is not clear." People want "is fierce disaster and zhi fu", is the key person of the executioner. Phase in the column": "poem" the so-called naturally Zheng people, objects are. Memorize is the body appearance is like class, bone method Angle of meat each have division, in the period of their lives, show the low table, one man's body, and the gas of the five lines of gossip." Features judge a tree by its bark, bones, color can 
show each person's life of die, also can accordingly to its fate. However, speculation and prediction did not necessarily translate into reality. Hereon, Wang Fu again mentioned that the fate lied in a person's own virtue. How to solve this problem? Wang Fu thought that it lied in the person cultivating their moral character and accumulating virtue. Thus, it can be seen that Wang Fu directly inherited Xun Zi's adapting the law of heaven and making use of it" and the basic idea of "man can conquer nature". And he put it as the starting point to interpret and analyze the four aspects of the customs on social divination, witchcraft, convinced, dream interpretation. Finally, the basic conclusion was that the four kinds of activities were not crush and trust. People's disaster and fortune cannot be decided through the warlock divination, wizard praying, speculation of face reading and the dream interpretation, but more relying on one's own virtue and his own efforts to determine their own destiny. For the prevail superstition in the feudal society, the average didn't have scientific and correct understanding. They saw it as a very natural and normal thing. But Wang Fu can put these seemingly ordinary problems to analyze and elucidate in a more scientific, accurate and reasonable ways. He concluded that people should give play to people's subjective initiative and meet their own destiny by cultivating morality, rather than relying on the superstitious activities. Lenin said that: "Judging historical merits and achievements, not according to the historical activists did not provide what modern required, but according to their provided new things than their predecessors" ${ }^{[4]}$ Although this conclusion was not a radical atheism thought, it was extremely excellent and very valuable in Chinese ancient history.

\section{References}

[1] Zhou Guixi. The New Study on Philosophical Thought of Wang Chong[M]. Shijiazhuang, Hebei Peoples Publishing House, 1984, 33-34.

[2] Zhou Guixi. The Intellectual History of Qin and Han Dynasties[M]. Shijiazhuang, Hebei Peoples Publishing House, 2000, 371.

[3] Wang Bugui. The Research on Thought of Wang Fu [M].Lanzhou, Gansu Peoples Publishing House, 1987, 82.

[4] [Soviet Union] Lenin. A Review on the Economic Romanticism. The Collected Works of Lenin (Volume II) [M].Beijing, Chinese People's Publishing House, 1959,150. 